\title{
Dual-Frequency, Dual-Polarization Microstrip Antenna Development for High- Resolution, Airborne SAR
}

\section{Granholm, Johan; Skou, N.}

\section{Published in:}

Proceedings of 2000 Asia Pacific Microwave Conference (APMC-2000)

Link to article, DOI:

10.1109/APMC.2000.925708

Publication date:

2000

Document Version

Publisher's PDF, also known as Version of record

Link back to DTU Orbit

Citation (APA):

Granholm, J., \& Skou, N. (2000). Dual-Frequency, Dual-Polarization Microstrip Antenna Development for HighResolution, Airborne SAR. In Proceedings of 2000 Asia Pacific Microwave Conference (APMC-2000) IEEE. https://doi.org/10.1109/APMC.2000.925708

\section{General rights}

Copyright and moral rights for the publications made accessible in the public portal are retained by the authors and/or other copyright owners and it is a condition of accessing publications that users recognise and abide by the legal requirements associated with these rights.

- Users may download and print one copy of any publication from the public portal for the purpose of private study or research.

- You may not further distribute the material or use it for any profit-making activity or commercial gain

- You may freely distribute the URL identifying the publication in the public portal 


\title{
DUAL-FREQUENCY, DUAL-POLARIZATION MICROSTRIP ANTENNA DEVELOPMENT FOR HIGH-RESOLUTION, AIRBORNE SAR
}

\author{
JOHAN GRANHOLM \& NIELS SKOU \\ Department of Electromagnetic Systems \\ Technical University of Denmark, DK-2800 Lyngby, Denmark \\ E-mail: jg@emi.dtu.dk
}

\begin{abstract}
The paper reviews recent work at the Technical University of Denmark, aimed at developing a true shared aperture, i.e. dual-frequency (L- and C-band), wideband, dual-linear polarization microstrip antenna array for use in the next-generation of the Danish high-resolution, airborne, polarimetric synthetic aperture radar (SAR) system. The dual-frequency array concept adopted relies on the use of probe-fed perforated, stacked patches for L-band $(1.2-1.3 \mathrm{GHz})$. Inside these perforations probe-fed, wideband stacked microstrip patches for C-band (4.9-5.7 GHz) are placed. Measured impedance and radiation pattern properties for this structure are reported.
\end{abstract}

\section{Requirements for future civilian SAR systems}

High-resolution airborne and spaceborne imaging of the Earth, for e.g. environmental studies, is often carried out using SAR techniques. Early SAR systems were single-frequency and single-polarization instruments, but time has seen a growing interest in multi-frequency, dual-polarization SAR systems. The reason for this trend is the additional amount of geophysical information, possibly to extract from multi-frequency, polarimetric SAR data. In recent years, technological research conducted by space agencies, as well as by other institutions, thus has been directed towards the development of such future multi-frequency, polarimetric SAR systems, [1] - [3].

Several multi-frequency, polarimetric SAR systems have already been built and flown, including the Danish L- and C-band system, EMISAR, which was developed at the Department of Electromagnetic Systems (EMI), [4]. All previous systems, however, have comprised a suite of stand-alone singlefrequency, polarimetric SAR's, each having had its own single-frequency antenna array. For this reason e.g. airborne multi-frequency data has often been acquired by repeatedly overflying and mapping the same area, using a different frequency each time. Doing so, however, the SAR data sets may render useless for intercomparison purposes, since temporal decorrelation can occur - e.g. due to rainfall between the passes. Therefore, from many points of view (aircraft installation and flight time, too), it is very desirably to acquire multi-frequency SAR data simultaneously. Hence, the advantages of polarimetric SAR's with shared-aperture, multi-frequency, dual-polarization antenna arrays are obvious in several respects, [1] - [3].

\section{Dual-frequency, dual-polarization microstrip antenna element}

A number of array topologies, potentially compliant with dual-frequency polarimetric SAR requirements, are reviewed in [5]. Different combinations of patches \& patches, slots \& patches and crossed dipoles \& patches are used for the low and high frequencies, respectively. Depending upon the frequency ratio between the frequency bands, some topologies may be more suitably than others; all offers advantages, and all suffers from disadvantages. Slot radiators or slot-fed elements (e.g. aperture coupled patches), both has the drawback that, in a practical antenna array, a closed cavity is required to be placed behind the slot or aperture. Such cavities may lead to a reduction of the bandwidth of the element, but worse they take up much valuable boardspace underneath the slot or aperture. The latter may prevent the layout of the (already challenging) multilayer beamforming network (BFN), which must reside under the groundplane with the slot. For this reason, slot-elements and aperture-coupled elements are not the obvious choice. Probe-fed patches are attractive from the feeding network point of view, since the probes can easily connect the patch to its BFN, which is e.g. located several layers down from the patch groundplane. Due to this and because of the $\approx 4: 1$ ratio between the L- and Cfrequency bands, it was decided to pursue the perforated patch combination, illustrated in Fig. 1. 

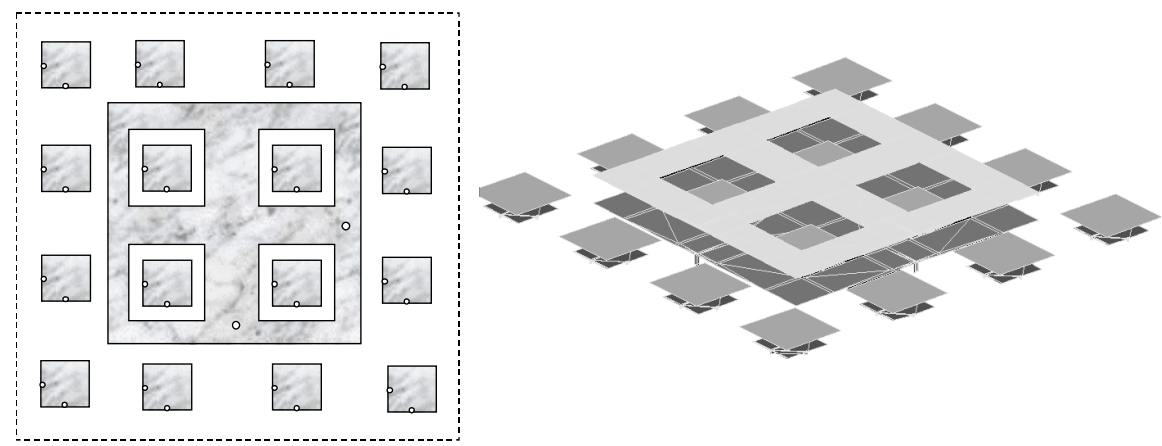

g) $0.1 \mathrm{~mm}$ FR4 (stacked L-band patch) f) $6 \mathrm{~mm}$ foam

e) $0.1 \mathrm{~mm}$ FR4 (stacked C-band patch) d) $2 \mathrm{~mm}$ foam

c) $0.1 \mathrm{~mm}$ FR 4 (driven L-band patch)

b) $2 \mathrm{~mm}$ foam

a) 32 mil RO4003 (driven C-band patch)

(bottom layer: Common groundplane)

Fig. 1. Dual-frequency "unit element": One perforated L-band patch and sixteen C-band patches.

A dual-frequency "unit element" consist of one perforated L-band patch with 4 C-band patches placed inside the perforations (or "windows") and surrounded by $12 \mathrm{C}$-band patches. All patches are driven from probes. To obtain the required impedance bandwidth, $8 \%$ in L-band and 15\% (goal) in C-band, stacked parasitic patches are necessary in both bands. Several combinations of having the driven and/or stacked L- and C-band patches sharing the same substrate layers have been studied. The "general" configuration, shown in Fig. 1b), with no such "substrate-sharing" imposed (i.e. all patches spaced independently) allows the largest degree of design-freedom, in this design otherwise full of constraints. In this case, the driven C-band patches were etched on 32 mil Rogers RO4003 $\left(\varepsilon_{\mathrm{r}}=3.38\right)$, with all remaining patches being etched on $0.1 \mathrm{~mm}$ FR4. Low-loss foam-substrate (Rohacell 31HF) with $\varepsilon_{\mathrm{r}}=1.05$ were used between the remaining layers. The final array for the SAR, [3], will have $8 \times 2$ elements in L-band and 32x8 elements in C-band, i.e. it will consist of 16 of the above "unit elements".

\section{L-band perforated, stacked microstrip patch \& 2x2 element sub-array}

Numerical techniques were found inefficient and unsuitable for the design of the stacked, perforated L-band element. An experimental approach was necessary. In Fig. $2(\mathrm{a}, \mathrm{b})$ is shown the measured Sparameters (in a $50 \Omega$ system) and the impedance of the stacked, perforated L-band patch of Fig. 1.
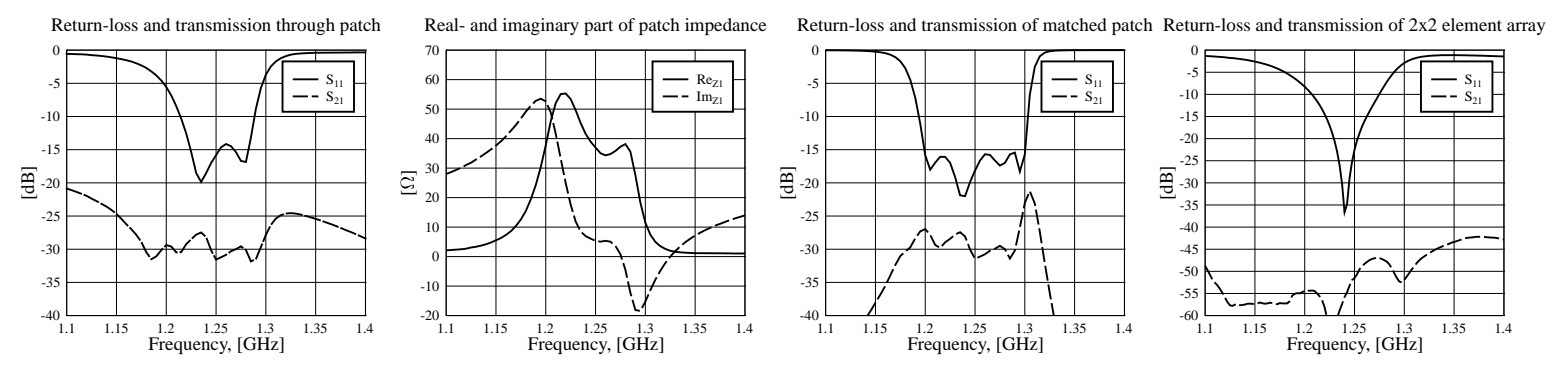

Fig. 2 Measured S-parameters and impedance of L-band stacked, perforated element and sub-array.

In Fig. 2b) two "peaks" in the real-part of the input impedance are seen. From experiments it was found: 1) The perforated, stacked patch exhibits two such resonances, but the "Q" of each is very high (depending on the size of the perforations), and it is not an easy task to obtain a wideband, wellbalanced (i.e. "stagger-tuned) behaviour with the two peaks having approximately the same value (as seen in Fig. 2b). Spacing the peaks further apart in frequency leads to a large variation in input impedance, preventing wideband performance to be achieved and instead turning the element into having "dual-resonance". 2) The transmission $\left(\mathrm{S}_{21}\right)$ through the stacked, perforated patch, the level of which has a major impact on the cross-polarization level of the element, exhibits two relatively wide "nulls", the location of which (in frequency) closely follows the peaks of the real-part of the input impedance. From cross-polarization considerations, this property is advantageous! Fig. 2c) shows what level of $S_{11}$ the element of Fig. 2a) can obtain, if implementing an external impedance-matching network. Although this result is so far theoretical, it clearly indicates that the element of Fig. 2a) may eventually be fully acceptable for use in the final array. The transmission between the C-band and the L-band elements was held below $-35 \mathrm{~dB}$ (in L-band), simply by short-circuiting to ground the centres 
of the C-band patches. These short-circuits had insignificant influence on the C-band patch performance. Leakage from C-band to L-band (i.e. in the $4.9-5.7 \mathrm{GHz}$ band) was prevented by using an open stub ( $\lambda / 4$ long in C-band), connected to the L-band probe feeding point.

A $2 \times 2$ element sub-array using four of the elements shown in Fig. 1 (spaced $150 \mathrm{~mm}$ apart; $0.625 \lambda_{0}$ at $1.25 \mathrm{GHz}$ ) was built to further investigate radiation pattern properties. The array was fed through a network made of coax-cables and -splitters. Fig 2d) shows the measured S-parameters of this array. Due to a very poor input match of the (commercially purchased) Wilkinson dividers, $S_{11}$ of the array is quite narrowbanded, but as indicated in Fig. 2c) this is not of concern at this time. More interesting is the very low level obtained for $\mathrm{S}_{21}$, being on the order of $-50 \mathrm{~dB}$ across the $1.2-1.3 \mathrm{GHz}$ band (compare to the isolated element, Fig. 2a). The improvement in $S_{21}$ of the array over $S_{21}$ of the isolated element is due to the cross-polarization suppression technique employed, [6], [7]. The radiation pattern of the stacked, perforated patch, and of the uniformly excited $2 \times 2$ element sub-array, is shown in Fig. 3. All pattern measurements were carried out in the spherical near-field test facility of EMI.
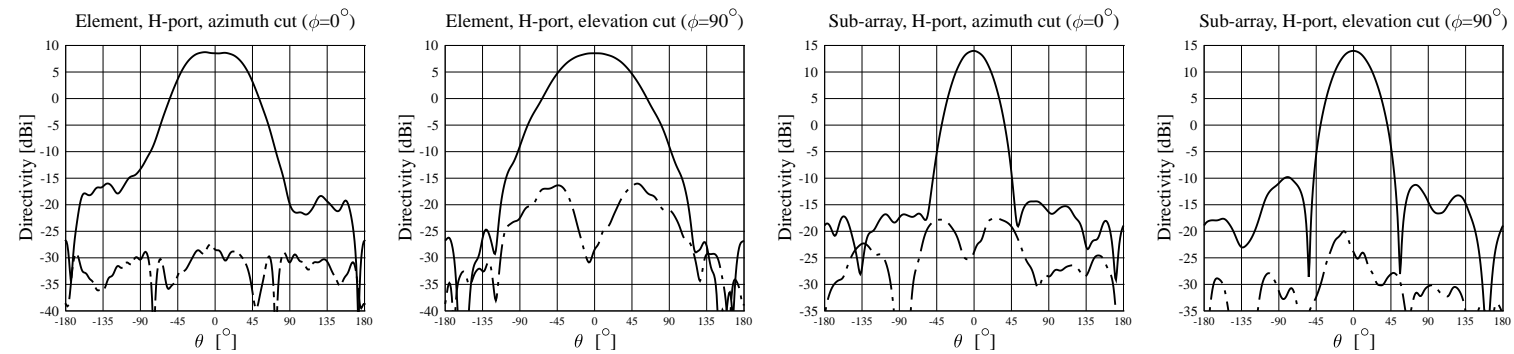

Fig. 3. Measured radiation pattern of L-band perforated, probe-fed patch element \& $2 \times 2$ ele. sub-array ( $\mathrm{f}=1.25 \mathrm{GHz}$ ). Size of array groundplane: $0.5 \times 0.5 \mathrm{~m}$. Horizontal polarization fed.

The stacked, perforated element has a "flat-topped" mainbeam pattern in the E-plane, and a fairly steep roll-off towards $\theta=90^{\circ}$. The latter characteristic is typical of stacked patches; the parasitic element help "focus" the energy which leads to better element directivity (comparing to an un-stacked, single element). The peak-directivity of the stacked, perforated patch is $\approx 8.5 \mathrm{dBi}$. Note the quite low cross-polarization level of the perforated patch. The $2 \times 2$ element sub-array pattern (Fig. 3c,d) is as expected; symmetrical with very low cross-polarization, [6], [7]. The radiation patterns (of both the element and the sub-array) was found to remain very stable over the $1.2-1.3 \mathrm{GHz}$ band.

\section{C-band stacked microstrip patch \& 4x4 element "interlaced" sub-array}

A wideband, probe-fed stacked microstrip patch for use in C-band (4.9-5.7 GHz) was designed, [8]. The unmatched return-loss, $S_{11}$, (in a $50 \Omega$ system) of this element was better than $-10 \mathrm{~dB}$ over an 860 $\mathrm{MHz}$ band, with $\mathrm{S}_{21}$ being below $-22 \mathrm{~dB}$ over the same band. The radiation pattern of the stacked Cband element (in a single, or "isolated", configuration) and of the $4 \times 4$ element sub-array embedded in/around the perforated L-band patch (i.e. the configuration shown in Fig. 1) is shown in Fig. 4.
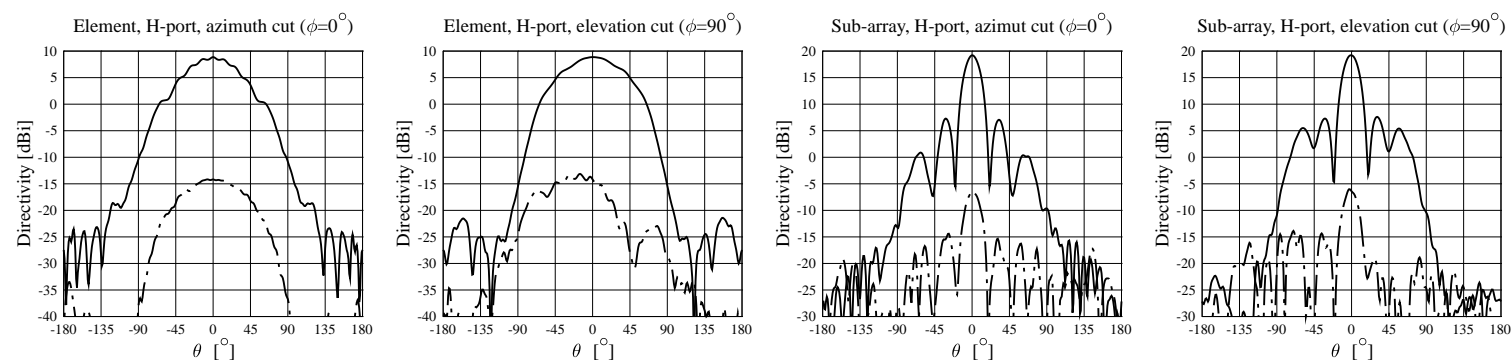

Fig. 4. Measured radiation pattern of C-band probe-fed patch and $4 \times 4$ element sub-array "unit element" ( $f=5.3 \mathrm{GHz})$. Size of array groundplane: 0.5 x $0.5 \mathrm{~m}$. Horizontal polarization fed.

The peak-directivity of the element is $\approx 9 \mathrm{dBi}$ with cross-polarization $\approx-23 \mathrm{~dB}$ in boresight (note that this value is very close to the level of $S_{21}$ ). The element pattern is almost constant over the $800 \mathrm{MHz}$ band. The $4 x 4$-element sub-array too was fed from a network made of coax-cables and -splitters, and 
was uniformously excited in both azimuth and elevation. No cross-polarization suppression technique was employed in this C-band sub-array. The element spacing was $150 \mathrm{~mm} / 4$, i.e. $0.62 \lambda_{0}$ at $5.3 \mathrm{GHz}$. In the E-plane of the sub-array (aziumth cut), it was observed that the perforated L-band element does not disturb the $\mathrm{C}$-band radiation pattern; the expected $\sin (\mathrm{x}) / \mathrm{x}$-shape is seen with fairly deep nulls. In the H-plane of the sub-array, however, it is seen that the "far out" sidelobes (at $\theta \approx 60^{\circ}$ ) are higher, and that the "far out" nulls are much less pronounced. Also, interestingly, the cross-polarization level of the $4 \times 4$ element "embedded" sub-array is not much different from that of the single, stacked patch. Due to the different surroundings of the 16 patches, their impedances (i.e. reflection coefficients) are not identical, hence some power is lost in the Wilkinson-dividers of the feeding network. This loss (incl. the $\approx 1 \mathrm{~dB}$ ohmic losses of the Wilkinson splitters themselves and of the coaxial cables) amount to $\approx 2.5 \mathrm{~dB}$ (quite constant across the $800 \mathrm{MHz}$ band, similar for both polarizations). Reducing the disturbance due to the L-band element by "shrinking" the outer periphery of the perforated patch and/or increasing the size of the perforations could, in principle, lower this loss, but both will impact the L-band resonance/bandwidth, and this idea therefore cannot be utilized. Another (hypothetical) possibility is to incorporate different impedance-matching networks for the patches with different impedances, but this will complicate array layout. It has not been investigated, if e.g. different stacked C-band elements may be used different places in the sub-array to achieve better impedance properties; this task is very complicated. It therefore appears necessary to accept some compromises, w.r.t. impedance variation of the C-band patches, if wideband operation in both $\mathrm{L}$ - and C-band is required.

\section{Conclusion}

The perforated L-band element has narrow bandwidth, but using a stacked configuration, and an external impedance matching network, the $8 \%$ target bandwidth is achievable. The element exhibits a well-behaved radiation pattern with good cross-polarization properties. The stacked C-band microstrip patch in a "stand-alone" case exhibits wideband performance (15\%), but is disturbed by the proximity of the perforated element, if the perforations and/or if the distance to the C-band element becomes too small. Yet, a wideband dual-frequency, dual-polarization L-/C-band array has been demonstrated.

\section{Acknowledgements}

This work was supported by the Danish National Research Foundation.

\section{References}

[1] National Aeronautics and Space Administration, "Spaceborne SAR : Current Status and Future Directions", NASA Technical Memorandum 4679, April 1995, http://southport.jpl.nasa.gov/nrc/

[2] European Space Agency, Industrial Policy Committee, "Dossier on High Resolution SAR technology", ESA/IPC (98)48, 1998, http://www.estec.esa.nl/xrmwww/Dossiers/IP9848e.pdf

[3] EMI, TUD, "Next-generation SAR", http://sarppsrv.emi.dtu.dk/ sarpp/

[4] E.L. Christensen, N. Skou, J. Dall, K. Woelders, J.H. Jørgensen, J. Granholm, S.N. Madsen, "EMISAR: An absolutely calibrated polarimetric L- and C-band SAR", IEEE Trans. on Geoscience and Remote Sensing Applications, Vol. 36, no. 6, Nov. 1998, pp. 1852-1865.

[5] J. Granholm, "Dual-frequency and dual-polarization antenna arrays for future SAR systems", 21st ESTEC Antenna Workshop on Array Antenna Technology (ESTEC publication WPP-142), Noordwijk, The Netherlands, 6-8 May 1998, pp. 29-35.

[6] J. Granholm, K. Woelders, "Dual-polarization antenna array with very low cross-polarization and low side lobes", International PCT Patent Application no. PCT/DK97/00141, filed March 26, 1997 (available at http://sarppsrv.emi.dtu.dk/ kw/patent/)

[7] K. Woelders, J. Granholm, "Cross-polarization and sidelobe suppression in dual linear polarization antenna arrays", IEEE Trans. on Antennas and Propagation, Vol. 45, No. 12, Dec. 1997, pp. 1727-1740.

[8] J. Granholm, N. Skou, "Probe-fed stacked microstrip patch antenna for high-resolution polarimetric C-band SAR", submitted for 2000 Asia Pacific Microwave Conference. 